\title{
Tumor Results Accepted Record Flag
}

National Cancer Institute

\section{Source}

National Cancer Institute. Tumor Results Accepted Record Flag. NCI Thesaurus. Code C117406.

An indication or description of a record that is considered to be the accepted and final evaluation for the tumor result. 